\title{
(2) OPEN ACCESS \\ Understanding decisions about antibiotic prescribing in ICU: an application of the Necessity Concerns Framework
}

- Additional supplemental material is published online only. To view, please visit the journal online (http://dx.doi. org/10.1136/bmjqs-2020012479).

For numbered affiliations see end of article.

\section{Correspondence to} Professor Robert Horne, University College London, London WC1E 6BT, UK: r.horne@ucl.ac.uk

This work was scheduled to be presented at the European Congress of Clinical Microbiology and Infectious Diseases conference in April 2020; this conference was cancelled due to the COVID-19 outbreak. This work was presented at the virtual International Symposium on Intensive Care and Emergency Medicine conference on September 15-18, 2020 and at the International Society for Medication Adherence conference on November 10-20, 2020.

Received 7 October 2020 Accepted 25 May 2021

\section{Check for updates}

(C) Author(s) (or their employer(s)) 2021. Re-use permitted under CC BY-NC. No commercial re-use. See rights and permissions. Published by BMJ.

To cite: Pandolfo AM,

Horne $R$, Jani $Y$, et al.

BMJ Qual Saf Epub ahead of print: [please include Day

Month Year]. doi:10.1136/

bmjqs-2020-012479

\section{Alyssa M Pandolfo (D) , ${ }^{1}$ Robert Horne, ${ }^{1}$ Yogini Jani, ${ }^{2}$ Tom W Reader, ${ }^{3}$ Natalie Bidad, ${ }^{1}$ David Brealey, ${ }^{4}$ Virve I Enne, ${ }^{5}$ David M Livermore, ${ }^{6}$ Vanya Gant, ${ }^{7}$ Stephen J Brett, ${ }^{8}$ INHALE WP2 Study Group}

\begin{abstract}
Background Antibiotics are extensively prescribed in intensive care units (ICUs), yet little is known about how antibiotic-related decisions are made in this setting. We explored how beliefs, perceptions and contextual factors influenced ICU clinicians' antibiotic prescribing. Methods We conducted 4 focus groups and 34 semistructured interviews with clinicians involved in antibiotic prescribing in four English ICUs. Focus groups explored factors influencing prescribing, whereas interviews examined decision-making processes using two clinical vignettes. Data were analysed using thematic analysis, applying the Necessity Concerns Framework. Results Clinicians' antibiotic decisions were influenced by their judgement of the necessity for prescribing/not prescribing, relative to their concerns about potential adverse consequences. Antibiotic necessity perceptions were strongly influenced by beliefs that antibiotics would protect patients from deterioration and themselves from the ethical and legal consequences of undertreatment. Clinicians also reported concerns about prescribing antibiotics. These generally centred on antimicrobial resistance; however, protecting the individual patient was prioritised over these societal concerns. Few participants identified antibiotic toxicity concerns as a key influencer. Clinical uncertainty often complicated balancing antibiotic necessity against concerns. Decisions to start or continue antibiotics often represented 'erring on the side of caution' as a protective response in uncertainty. This approach was reinforced by previous experiences of negative consequences ('being burnt') which motivated prescribing 'just in case' of an infection. Prescribing decisions were also context-dependent, exemplified by a lower perceived threshold to prescribe antibiotics outof-hours, input from external team members and local prescribing norms.

Conclusion Efforts to improve antibiotic stewardship should consider clinicians' desire to protect with a prescription. Rapid molecular microbiology, with appropriate communication, may diminish clinicians' fears of not prescribing or of using narrower-spectrum antibiotics.
\end{abstract}

\section{INTRODUCTION}

Intensive care units (ICUs) are unique environments where clinicians often make antibiotic decisions under diagnostic uncertainty and with high-stakes consequences. During decision-making, intensivists must balance heightened priorities of patients' needs with antimicrobial stewardship (AMS) initiatives; how ICU doctors navigate these trade-offs remains poorly understood.

Critical care patients frequently exhibit 'traditional' signs of infection (eg, fever) even when no infection is present; consequently differentiating infection from non-infectious conditions is challenging. ${ }^{1}$ Furthermore, infections may be viral rather than bacterial, with only the latter requiring antibiotics. Undertreating bacterial infections or delaying antibiotics in ICU may increase the risk of mortality ${ }^{2}$; conversely, unnecessary therapy increases the risk of antibiotic-related side effects, including adverse drug reactions and infection with Clostridium (Clostridiodes) difficile, ${ }^{3}$ and promoting antimicrobial resistance (AMR). ${ }^{4}$

The development of AMR is of particular concern in ICU. Many patients have multiple comorbidities, histories of frequent hospital admissions, long hospital and ICU stays, multiple prior antibiotic courses, and complex physiologies; these factors can lead to underdosing and overdosing and are ideal circumstances for antibiotic toxicity and AMR development. These risks are compounded by invasive device usage, high broadspectrum antibiotic exposure and ICU treatment intensity. ${ }^{5}$ Consequently, intensivists have seen an increasing prevalence of resistance and treatments failing due to AMR. $^{6}$ 
Accordingly, antibiotic decisions have high levels of consultant intensivist and microbiologist involvement, and ICU-specific AMS programmes have been developed. ${ }^{78}$ Yet up to $70 \%$ of ICU patients receive antimicrobial therapy, ${ }^{9}$ despite up to half having no confirmed infection. ${ }^{2}$

Outside the ICU, studies have identified the importance of clinicians' beliefs about their prescribing's consequences, ${ }^{10}$ AMR perceptions, ${ }^{11}$ and social and professional influences. ${ }^{12}$ However, these studies have variously excluded intensivists, ${ }^{13}$ combined ICU and non-ICU wards, ${ }^{14} 15$ only included non-ICU wards, ${ }^{16} 17$ or did not specify which wards were included. ${ }^{18}$

The Necessity Concerns Framework (NCF) may help to understand antibiotic decision-making. Extensively used to understand patients' medication adherence, NCF posits that decisions to start and continue with treatments are influenced by how individuals judge the necessity for treatment relative to their concerns about the actual or potential adverse consequences of taking it. $^{19}$

Like Hulscher and colleagues, ${ }^{12}$ we applied a social and behavioural approach investigating clinicians' perspectives of antibiotic decision-making ('clinician perceptions') and the social and environmental aspects surrounding these perceptions ('contextual factors'). We explore these factors' influence on ICU antibiotic decision-making, interpreting our findings using NCF.

\section{METHODS}

This research is part of the INHALE programme (ISRCTN16483855) investigating molecular diagnostic utility for pneumonias in ICU. ${ }^{20}$ A randomised controlled trial is being conducted whereby patients with suspected pneumonias are randomised to receive either standard care or decision-making support from a point-of-care molecular diagnostic test. A behavioural evaluation examines antibiotic decision-making and clinicians' willingness to adopt molecular tests. Before the trial, we strove to understand how ICU antibiotic decisions were made.

This study is reported following the Standards for Reporting Qualitative Research guidelines. ${ }^{21}$ It used focus groups and vignette-based interviews (VBIs) and followed a contextualist approach positing that the external context affects individuals' interpretation of their experiences. ${ }^{22}$ All participants provided informed consent.

\section{Study design}

Focus groups explored contextual factors perceived to influence antibiotic decisions. Through these discussions, clinicians shared and compared their prescribing attitudes and experiences, allowing exploration of a range of perspectives (see online supplemental table S1 for topic guide). ${ }^{23}$

Interviews investigated antibiotic decision-making processes. These used clinical vignettes depicting hypothetical but realistic scenarios at key decision points (see online supplemental table S2 for vignettes and interview guides). Individuals applied their expertise and experience to determine a course of action based on provided information, followed by a wideranging and detailed discussion around raised issues. Cognitive processes elicited during VBIs simulate realworld decision-making, ${ }^{24}$ and researchers can compare participants' responses and systematically reconstruct decision-making processes.

\section{Sample and setting}

This research occurred in the ICUs of four English hospitals (see table 1 for the characteristics). We chose these sites due to their differences in patient populations and in general prevalence of resistant bacteria. Convenience sampling was used; clinicians participated whenever they could spare time from clinical duties. Focus groups were prescheduled, whereas VBIs were opportunistic. NB, YJ and DB recruited participants through local promotion; NB and $\mathrm{YJ}$ have clinical pharmacy backgrounds and DB is an ICU consultant at a participating site.

In UK ICUs, consultants ('attending' level permanent staff with usually over 10 years of experience) make most antibiotic decisions, aided by visiting clinical microbiologists, typically consultant level. ICUs are 'closed units' - consultant intensivists have ultimate decision-making power for patients. Members from teams like microbiology and surgery can give recommendations but cannot change aspects of the patient's management without consultant intensivist permission. ICU middle-grade (5-7 years of experience) and early-grade (up to 4 years of experience) trainees occasionally make antibiotic decisions, usually in urgent out-of-hours settings. Pharmacists aid with dosing and monitoring antibiotics, including choice and treatment durations.

All staff involved in ICU antibiotic prescribing could participate in focus groups; recognising that decision-making involves the team, non-prescribers were included. VBI participants were individuals who would actively prescribe on ICU (ie, consultant intensivists and trainees).

\section{Data collection}

$\mathrm{NB}$ and YJ conducted all focus groups and VBIs. Focus groups were semistructured and began with 'What factors do you think influence your decisions around antimicrobial prescribing on your ICU?' The moderators used predetermined follow-up prompts about contextual factors influencing prescribing. One focus group was conducted at each site; three were face-toface and one was a teleconference. Four focus groups were deemed sufficient as previous research found that all prevalent themes could be identified in three. ${ }^{25}$ Focus groups lasted between 25 and $45 \mathrm{~min}$ and were undertaken between August and September 2018. 


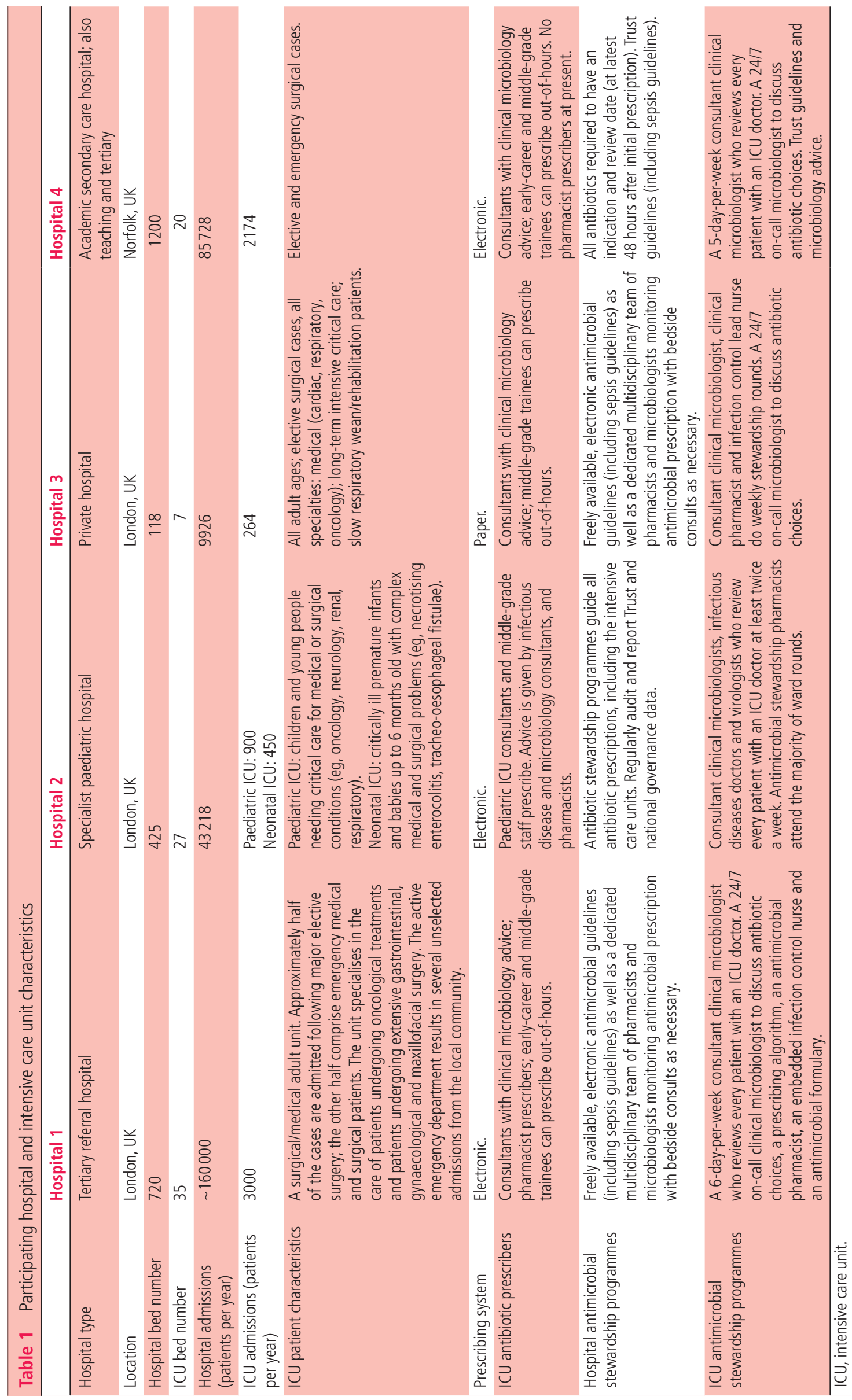


Semistructured interviews explored decision-making processes using two vignettes. Vignette 1 related to whether to start a patient on antibiotics, whereas vignette 2 depicted a patient currently on antibiotics where clinicians could choose to continue, change or stop antibiotics. Both patients had lower respiratory tract infections; these are common to ICU and are associated with diagnostic uncertainty. These scenarios had no 'correct' answers; rather, their purpose was to encourage reflection on decision-making processes. Five non-participating consultant intensivists pilottested the vignettes to ensure they were realistic and included sufficient information.

Paediatric clinicians were given analogous vignettes depicting children; otherwise, the same interview guides were used for all participants. VBIs were conducted face-to-face in each ICU, lasted between 7 and $40 \mathrm{~min}$, and occurred between August and December 2018. Interviews and coding were iterative, with interviews conducted until data saturation (three consecutive interviews resulting in redundant information). ${ }^{26}$

\section{Data analysis}

All focus groups and interviews were audio-recorded, anonymised, professionally transcribed and entered into NVivo V.12. AMP (research psychologist), NB and YJ verified transcript accuracy. Data were first analysed using inductive thematic analysis, with themes constructed at a semantic level summarising content explicitly discussed by multiple clinicians. ${ }^{27}$

Data were open-coded, with codes refined and themes formed with input from the multidisciplinary team (see online supplemental table S3 for disciplines). We then adopted a deductive approach interpreting the generated themes using NCF. ${ }^{28}$ For instance, themes related to clinicians' beliefs of antibiotic importance were classified as necessity perceptions. As focus group participants discussed their perceptions and VBI participants mentioned contextual factors, we treated both data sources as equally important and triangulated our findings between them. ${ }^{29}$

AMP conducted analyses, aided by NB, following Braun and Clarke's ${ }^{30}$ approach: data familiarisation, generating codes, searching for themes, reviewing and defining themes, and writing the report.

\section{RESULTS}

Audio recording duration was approximately 2.6 hours for focus groups and 9 hours for VBIs. Focus group participants largely agreed with each other; there were few if any points of tension. Table 2 shows participants' characteristics.

Our overarching finding was that clinicians favoured starting or continuing antibiotics in uncertainty. Prescribing antibiotics was often perceived as necessary to protect patients and clinicians from deleterious immediate consequences. If clinicians were uncertain
Table 2 Characteristics of study participants

\begin{tabular}{|c|c|c|}
\hline & Focus groups & $\begin{array}{l}\text { Vignette-based } \\
\text { interviews }\end{array}$ \\
\hline $\begin{array}{l}\text { Number of } \\
\text { participants }\end{array}$ & $\begin{array}{l}\text { Total: } 26 \\
\text { Hospital 1: } 11 \\
\text { Hospital } 2^{*}: 5 \\
\text { Hospital 3: } 5 \\
\text { Hospital 4: } 5\end{array}$ & $\begin{array}{l}\text { Total: } 34+ \\
\text { Hospital } 1: 11 \\
\text { Hospital } 2: 10 \\
\text { Hospital } 3: 7 \\
\text { Hospital } 4: 6\end{array}$ \\
\hline $\begin{array}{l}\text { Participants' } \\
\text { rolesł }\end{array}$ & $\begin{array}{l}\text { Hospital 1: } 5 \text { ICU consultants, } \\
2 \text { ICU middle-grade trainees, } \\
1 \text { ICU early-career trainee, } \\
1 \text { clinical microbiologist, } 1 \\
\text { ICU pharmacist, } 1 \text { health } \\
\text { psychologist. } \\
\text { Hospital 2: } 1 \text { ICU consultant, } 3 \\
\text { ICU pharmacists, } 1 \text { infectious } \\
\text { diseases consultant. } \\
\text { Hospital 3: } 2 \text { ICU middle-grade } \\
\text { trainees, } 2 \text { ICU pharmacists, } 1 \\
\text { nurse. } \\
\text { Hospital 4: } 2 \text { ICU consultants, } \\
1 \text { ICU middle-grade trainee, } 1 \\
\text { clinical microbiologist, } 1 \text { ICU } \\
\text { pharmacist. }\end{array}$ & $\begin{array}{l}\text { Hospital 1: } 4 \text { ICU } \\
\text { consultants, } 4 \text { ICU } \\
\text { middle-grade trainees§, } \\
3 \text { ICU early-career } \\
\text { trainees. } \\
\text { Hospital 2: } 3 \text { ICU } \\
\text { consultants, } 7 \text { ICU } \\
\text { middle-grade trainees. } \\
\text { Hospital 3: } 2 \text { ICU } \\
\text { consultants, } 5 \text { ICU } \\
\text { middle-grade trainees. } \\
\text { Hospital 4: } 2 \text { ICU } \\
\text { consultants, } 4 \text { ICU early- } \\
\text { career trainees. }\end{array}$ \\
\hline
\end{tabular}

*All clinicians from hospital 2 care for paediatric patients; the remainder treat adults.

tInterviews occurred individually except in one case where one earlycareer trainee and one middle-grade trainee were interviewed together. ‡One consultant from hospital 1 and one from hospital 4 participated in both the focus groups and interviews.

$\S$ Two middle-grade trainees were only able to complete vignette 1 owing to clinical pressures on the unit.

ICU, intensive care unit.

whether antibiotics were required, they favoured 'erring on the side of caution':

the easy default is to give an antibiotic and if you're confident or overconfident or deluded or whatever, you sometimes hold. -P52, consultant, hospital 1, focus group

it's 48 hours [until culture results come back]. I think you've got more tendency to try and prescribe something [antibiotics] just because it's going to be... Until you know exactly there's nothing going on. P47, early-career trainee, hospital 4, VBI

I think they [intensivists] would be always being erring on the side of caution, you wouldn't even stop it [antibiotics] if there is any suspicion of risk. - $\mathrm{P} 40$, pharmacist, hospital 2, focus group

Clinicians' perceptions of antibiotic necessity outweighing antibiotic-related concerns underscore erring on the side of caution. Contextual factors also influenced this inclination to prescribe in uncertainty. We describe both themes in the following sections.

\section{Clinician perceptions of antibiotic necessity outweighing concerns}

Perceptions of the necessity to prescribe were related to beliefs that, in uncertainty, antibiotics provide protection for patients and clinicians. Clinicians were 
Table 3 Supporting quotations for clinician perceptions theme

\begin{tabular}{|c|c|}
\hline Subtheme & Supporting quotations \\
\hline \multirow[t]{3}{*}{$\begin{array}{l}\text { Necessity to protect } \\
\text { patients }\end{array}$} & $\begin{array}{l}\text { 1. "I mean she has already gone on meropenem. So, it might be that it was keeping something [infection] at bay. And then it has } \\
\text { been stopped. And that infection has re-developed." - P57, middle-grade trainee, hospital 3, VBI }\end{array}$ \\
\hline & $\begin{array}{l}\text { 2. "I think a four days' course of antibiotics is going to lead to resistance if anything because he's not completed a full course } \\
{[\ldots \text {... In this situation there's not really been a bug, so I think a seven-day minimum [course] would be appropriate." —P22, }} \\
\text { middle-grade trainee, hospital 3, VBI }\end{array}$ \\
\hline & $\begin{array}{l}\text { 3. "Maybe they've got a minor infection, it will self-resolve without any antibiotics, but maybe [with antibiotics] you'll get an } \\
\text { extra day or so where the patient is now considered safe for discharge. And so, you've accelerated the discharge and so there's } \\
\text { a whole process of flowing the patient through the hospital and progressing them. And ultimately not exposing them to an } \\
\text { environment in which they are at risk of actually picking up a nosocomial infection." -P43, consultant, hospital 1, VBI }\end{array}$ \\
\hline \multirow[t]{2}{*}{$\begin{array}{l}\text { Necessity to protect } \\
\text { clinicians }\end{array}$} & $\begin{array}{l}\text { 4. "One of the questions that I was grilled on in the Coroner's court last Monday was 'Why are we stopping antibiotics? If he } \\
\text { had such a bad infection, why did we stop the antibiotics?" - P28, consultant, hospital 1, FG }\end{array}$ \\
\hline & $\begin{array}{l}\text { 5. "I don't know if you've heard about the Sepsis Six? [...] if you decided not to start antibiotics, I don't know where you would } \\
\text { stand, I don't think you would have a leg to stand on at all." —P10, consultant, hospital 2, FG }\end{array}$ \\
\hline \multirow[t]{3}{*}{$\begin{array}{l}\text { Antibiotic-related } \\
\text { concerns not prioritised }\end{array}$} & $\begin{array}{l}\text { 6. "[...] when I have a patient, and the patient is deteriorating, I just focus on that patient. I don't think, 'What's the impact of } \\
\text { starting this or that antibiotic on the whole ecology of the unit?' I don't bother because, to be honest, my focus is that patient." } \\
\text { _P1, consultant, hospital 3, VBI }\end{array}$ \\
\hline & $\begin{array}{l}\text { 7. "[...] we're creating our own monster [antimicrobial resistance] because we're throwing around antibiotics." —P11, } \\
\text { consultant, hospital 1, FG }\end{array}$ \\
\hline & $\begin{array}{l}\text { 8. "I'd want them to have antibiotics. Despite the fact that there is this theoretical risk of resistance." —P36, consultant, hospital } \\
\text { 2, VBI }\end{array}$ \\
\hline \multirow[t]{4}{*}{$\begin{array}{l}\text { Being brave vs being } \\
\text { burnt }\end{array}$} & $\begin{array}{l}\text { 9. "It can be, sometimes, more helpful to start with a more focused [narrower spectrum] antibiotic rather than muddle the } \\
\text { picture with empirical antibiotics. But that takes a certain amount of bravery." - P3, early-career trainee, hospital 1, VBI }\end{array}$ \\
\hline & 10. "So, I, my gut feeling, so I'm 70\% certain he doesn't need antibiotics now." —P6, consultant, hospital 3, VBI \\
\hline & $\begin{array}{l}\text { 11. "Maybe I'm not yet at the stage where I'd be brave enough to start nothing [no antibiotics]. I would like to be. I think we } \\
\text { give far too many antibiotics. But I'm probably not at that stage yet. [...] Probably, in this particular instance, I don't think you'd } \\
\text { be able to get away with not starting antibiotics at all. Because she's become so unwell, she's intubated. I think what makes you } \\
\text { more brave in your decision-making is experience." —P35, middle-grade trainee, hospital 2, VBI }\end{array}$ \\
\hline & $\begin{array}{l}\text { 12. "There's definitely cases where you're brave until you're burnt and then you stop being brave. And you only have to have } \\
\text { one, I had one recently where I just didn't spot it as being sepsis and the guy died overnight." -P48, consultant, hospital 1, FG }\end{array}$ \\
\hline
\end{tabular}

FG, focus group; VBI, vignette-based interview.

aware of and concerned about AMR, whereas they seldom mentioned concerns about the potential for antibiotics resulting in patient harm as key considerations. Concerns about antibiotic harm (individual and societal) were rarely prioritised to a degree where they outweighed perceived necessity, enabling clinicians to 'be brave' by withholding or stopping antibiotics. This encouraged antibiotic prescription and continuation in an approach characterised by erring on the side of caution. Table 3 shows supporting quotes.

Antibiotic necessity: prescribing protects patients against adverse consequences

When discussing antibiotic prescription, clinicians used the language of protection against adverse consequences rather than of actively 'curing' patients of infections. Decisions to start or continue antibiotics were influenced by the perception that antibiotics were necessary to prevent patient deterioration and mortality from infections (quote 1, table 3 ). Continuing antibiotics, rather than stopping early, was perceived as necessary to prevent AMR (quote 2, table 3). If clinicians were more certain of whether a patient had a bacterial infection or if they felt the course was completed and the antibiotics had led to clinical improvement, most were confident to stop (or withhold further) antibiotics. However, a minority viewed prescribing antibiotics as necessary 'just in case', despite believing that they were not currently required (quotes $2-3$, table 3 ).

Antibiotic necessity: prescribing protects clinicians against adverse consequences

Clinicians believed that prescribing antibiotics was necessary to protect themselves when retrospectively defending their decision. Under uncertainty, prescribing or continuing antibiotics was generally perceived to be most defensible. Some consultants recounted interrogations in the coroner's court about why they stopped or did not prescribe antibiotics (quote 4, table 3). None described being questioned for starting or continuing antibiotics.

Prescribing consistent with particular policies was perceived as defensible. One frequently raised national policy was Sepsis Six, which states that if a patient is thought to be septic, clinicians must prescribe empiric antibiotics within an hour. ${ }^{31}$ Some clinicians thus felt pressured to start antibiotics urgently because they believed that this behaviour was the most defensible (quote 5, table 3). This $60 \mathrm{~min}$ target is also a National Institute for Health and Care Excellence quality standard. $^{32}$ 
Concerns about prescribing's adverse consequences: AMR and antibiotic toxicity

Clinicians' predominant concern was AMR; they were aware of resistance and valued protecting antibiotic choice and efficacy. Despite perceiving AMR as important, these concerns were over-ridden by perceptions of antibiotic necessity to protect the patient and the clinician (quote 6 , table 3 ). AMR concerns were moderated by perceptions of personal responsibility and accountability. Clinicians saw antibiotics as preventing consequences for which they were immediately responsible, with safeguarding the patient perceived as the overriding priority. They saw preventing AMR as distal to this aim and less of an immediate priority. There was variation between clinicians regarding the importance of AMR in prescribing decisions for individual patients. Some doctors saw strong links between their own prescribing and AMR (quote 7, table 3), whereas a minority felt less personally responsible for AMR and doubted whether resistance would occur (quote 8, table 3).

Unlike AMR, antibiotic toxicity concerns were infrequent. Strikingly, 3 out of 35 clinicians raised antibiotic-related adverse effects in their VBI. The remainder did not mention potential antibiotic side effects as a decision-making consideration.

Balancing necessity and concerns: 'being brave' versus 'being burnt' In uncertainty, clinicians were motivated to prescribe antibiotics empirically to protect against undesirable consequences. Nonetheless, they also valued using antibiotics carefully to protect their unit's ecology. In contrast to prescribing and continuing antibiotics when uncertain, clinicians referred to withholding and stopping potentially unnecessary antibiotics as 'bravery' (quote 9, table 3). Framing 'conservative' prescribing as bravery illustrates clinicians' expectations of adverse consequences resulting from not prescribing; this language highlights clinicians' strong beliefs about antibiotics' necessity despite acknowledgement of antibiotic-related concerns.

Bravery was believed to improve with clinical experience. Consultants described a 'gut feeling' they used to make decisions (quote 10, table 3); trainees recognised bravery's benefits but worried about possible consequences of not prescribing (quote 11, table 3).

Negative experiences may over-ride this bravery. Previously 'being brave' with antibiotics but experiencing negative consequences may stifle clinicians' bravery with future patients (quote 12, table 3). 'Being burnt' appears to have motivated consultants to revert to prescribing or continuing antibiotics in future patients in uncertainty. Experiencing adverse personal consequences after not prescribing may strengthen antibiotic necessity perceptions, discouraging bravery in future decisions.

\section{Contextual factors}

The decision-making context moderated clinicians' necessity and concerns perceptions. It could either reinforce or over-ride inclinations to prescribe in uncertainty. Contextual factors include decision-making in-hours versus out-of-hours, input from external team members and ICU prescribing norms.

Table 4 shows supporting quotations.

Decision-making in-hours versus out-of-hours

In-hours, clinicians felt more confident to withhold antibiotics in uncertainty. On weekdays, consultant intensivists typically made antibiotic decisions with clinical microbiology involvement. Early-career and middle-grade trainees reported having little input (quotes 13-14, table 4). In-hours decisions were seen as more judicious than out-of-hours decisions, with clinicians having higher thresholds to prescribe antibiotics during 'core hours' (quote 15, table 4).

For out-of-hours prescribing, consultants provide contingency 'SOS plans' for early-career and middlegrade trainees, to whom decision-making responsibility falls. If trainees felt confident, they could prescribe without input; otherwise, they were expected to contact on-call ICU and microbiology consultants. Some perceived variation in consultants' expectations about being called and worried about disturbing them at night (quote 16, table 4).

If trainees felt unable to access consultant support, they were likely to start or continue antibiotics empirically. Many viewed prescribing antibiotics as 'safest', favouring broad-spectrum antibiotics which they believed were less risky than narrow spectrums (quote 17, table 4). These beliefs illustrate trainees' strong necessity beliefs out-of-hours; they also anticipated that consultants would overturn inappropriate prescriptions in-hours (quote 14, table 4).

Input from external team members

Clinicians reported that external team membersgenerally clinical microbiologists and pharmacistsoften increased intensivists' confidence about withholding or stopping potentially unnecessary antibiotics. These 'antimicrobial stewards' would challenge potentially inappropriate antibiotic decisions, remind clinicians about local AMR rates and reach a consensus about antibiotics with consultant intensivists (quote 18, table 4). Consultant intensivists appreciated these negotiations and occasionally would await this input before making decisions.

There were some points of tension regarding clinical microbiology advice. As microbiologists did not usually examine patients, certain clinicians worried that microbiology recommendations relied on potentially inaccurate or incomplete information from ICU trainees (quote 19, table 4). Similarly, certain consultants expressed concerns that some trainees followed microbiology recommendations without checking 
Table 4 Supporting quotations for contextual factors theme

\begin{tabular}{|c|c|}
\hline Subtheme & Supporting quotations \\
\hline \multirow{5}{*}{$\begin{array}{l}\text { Decisions in- } \\
\text { hours vs out-of- } \\
\text { hours }\end{array}$} & $\begin{array}{l}\text { 13. "Most antibiotic decisions are made by microbiology or the consultant rather than us. On the wards it'd be different, it'd be more us, but ove } \\
\text { here everything's passed on to someone more senior." - P27, early-career trainee, hospital 1, VBI }\end{array}$ \\
\hline & $\begin{array}{l}\text { 14. "I would like to use slightly less strong antibiotics, but I'm not allowed to. [...] if you make the decision out-of-hours it'll get changed back } \\
\text { in-hours. It's made by the consultants and they rely a lot on microbiology [...] there's very little independence in decision-making in an intensive } \\
\text { care unit on a junior level." —P35, middle-grade trainee, hospital 2, VBI }\end{array}$ \\
\hline & $\begin{array}{l}\text { 15. "[...] during the day, there're lots of bosses around, and you'd get to phone up micro, and there'd be someone on the micro ward round. } \\
\text { Then you might be helped, you know might... the consultant might take the decision to be...to hold steady, wait for a bit longer, wait for these } \\
\text { results to come back. And then take a decision. But if it was just down to skeleton crew, a couple of SHOs [early-career trainees] and the Reg. } \\
\text { [middle-grade trainee], in the middle of the night, three or four, after the consultant probably has gone to bed, the Reg. might take the decision } \\
\text { that actually we're just going to [prescribe antibiotics]." - P3, early-career trainee, hospital 1, VBI }\end{array}$ \\
\hline & $\begin{array}{l}\text { 16. "[...] you are always less likely to phone a consultant in the middle of the night for advice because you are more worried about disturbing } \\
\text { them. [...] It's when you feel like you're on your own and you can't get it in touch with anyone else, that's when I think you err on the side of } \\
\text { caution and you prescribe [antibiotics]." —P25, middle-grade trainee, hospital 3, FG }\end{array}$ \\
\hline & $\begin{array}{l}\text { 17. "[...] out-of-hours or what have you, when you haven't got all of the support around decision making that you might want, your primary air } \\
\text { is to do something which is safest for the patient in front of you [...] [which] is to give them the broadest spectrum [antibiotic] you can at the } \\
\text { time." - P15, middle-grade trainee, hospital 3, VBI }\end{array}$ \\
\hline \multirow[t]{8}{*}{$\begin{array}{l}\text { Input from } \\
\text { external teams }\end{array}$} & $\begin{array}{l}\text { 18. "If you go on [Consultant Microbiologist]'s ward round and no one can, eh, say why the antibiotics, what it's for, or when it's going to stop, } \\
\text { then that's a good thing to challenge. And I think that probably has resulted in us shaving a few days of antibiotic usage and therefore, last year } \\
\text { achieving that [quality service initiative]." - P38, consultant, hospital 1, FG }\end{array}$ \\
\hline & $\begin{array}{l}\text { 19. "[...]micro base it [antibiotics] on the information they're given by the registrars and their decision will be as good as the information that } \\
\text { they get." } \\
\text { —P10, consultant, hospital 2, FG }\end{array}$ \\
\hline & $\begin{array}{l}\text { 20. "[Early-career and middle-grade trainees are] just happy to take opinions from other people and just do that and just say it was suggested b } \\
X, Y \text {, and Z, and that's why we've done it. So, I think we've actually lost our skills as clinicians [...] If it's something to do with nutrition, they say } \\
\text { tell the dietician. If it's something to do with antibiotics, tell the microbiologist." —P8, consultant, hospital } 4, \mathrm{VBI}\end{array}$ \\
\hline & 21. "I don't feel that confident about getting the right antibiotic. I'd want to get micro involved." —P57, middle-grade trainee, hospital 3, VBI \\
\hline & $\begin{array}{l}\text { 22. "[...] it's very rare that surgical prophylaxis will continue past } 24 \text { hours. There's one particular gastro-intestinal surgeon who does five or } \\
\text { seven days for his hepatectomies and stuff and try as we might we can't get that stopped." —P5, pharmacist, hospital 3, FG }\end{array}$ \\
\hline & $\begin{array}{l}\text { 23. "It's a bit of a consensus, isn't it? We try hard not to have a massive fight. We try and persuade people. I wouldn't go up to a haematologist } \\
\text { very often and insist they stopped all the antibiotics and say, well, even if you're not, I'm going to. Well, you're on my ward - that wouldn't } \\
\text { happen. It's kind of well we think there's no good reason, can we [stop antibiotics]?" —P48, consultant, hospital 1, FG }\end{array}$ \\
\hline & $\begin{array}{l}\text { 24. "Most of the time, we're fighting off external pressure to change - to either crank up or put two antibiotics or start them inappropriately. } \\
\text { We've got lots of physicians that seem to think that everybody needs an antibiotic when there's [something] wrong with them which we'll resist } \\
\text { quite strongly." - P29, consultant, hospital 4, FG }\end{array}$ \\
\hline & $\begin{array}{l}\text { 25. "[...] the trouble is if you stop the antibiotic on a haematology patient and something goes wrong, then you're automatically in firing lines. } \\
\text { So, I don't think anybody does tend to." -P17, microbiologist, hospital 1, FG }\end{array}$ \\
\hline \multirow[t]{6}{*}{$\begin{array}{l}\text { ICU prescribing } \\
\text { norms }\end{array}$} & $\begin{array}{l}\text { 26. "[...] here, there's been a lot more of a push to get a clearer idea of the source before you start [antibiotics]." —P44, middle-grade trainee, } \\
\text { hospital 1, VBI }\end{array}$ \\
\hline & $\begin{array}{l}\text { 27. "[...] we're really tightly controlled here for antibiotics. There isn't much leeway. [...] Co-amox [iclav] is in the corner [i.e., banned], we're no } \\
\text { allowed to touch it. [...] You get a slap on the wrist if you deviate from the guidelines." —P20, early-career trainee, hospital 4, VBI }\end{array}$ \\
\hline & $\begin{array}{l}\text { 28. "[In this ICU] the use of antibiotics is far more widespread and so you would be against the grain if you didn't use them. So, you would be } \\
\text { not part of normal practice." - P54, middle-grade trainee, hospital 2, VBI }\end{array}$ \\
\hline & $\begin{array}{l}\text { 29. "For me, at least, I would like to stop as soon as possible, for every antibiotic, especially if it was given empirically. I think many times we jus } \\
\text { continue antibiotics when it's [sic] uncalled for." - P23, middle-grade trainee, hospital 2, VBI }\end{array}$ \\
\hline & $\begin{array}{l}\text { 30. "You have to go with your hospital protocol because it's designed with your patient demographics in mind." —P21, middle-grade trainee, } \\
\text { hospital 3, VBI }\end{array}$ \\
\hline & $\begin{array}{l}\text { 31. "There are some guidelines but they're not really go-to guidelines for intensive care as they are on AMU [acute medical unit] and throughou } \\
\text { the hospital. I think they're a bit looser. I think it's more individually decided upon. On the ward there are guidelines, but they are pretty much } \\
\text { everyone follows that line unless you've got something very unusual. Whereas on ICU it's not like we have a set of guidelines that we generally } \\
\text { go down that line." - P51, consultant, hospital 1, FG }\end{array}$ \\
\hline
\end{tabular}

FG, focus group; ICU, intensive care unit; $\mathrm{VBI}$, vignette-based interview.;

or understanding the rationale (quote 20, table 4). Trainees valued microbiology input, but some felt deskilled in their independent prescribing abilities because of this support (quotes 20-21, table 4).

Other external team members would forcefully advocate inappropriate decisions, which included starting, adding and continuing potentially unnecessary antibiotics. For instance, one surgeon would insist on multiple days of prophylaxis, although local practice was 24 hours (quote 22, table 4). Although ICU consultants had the ultimate decision, none reported over-ruling the external party. Rather, they would negotiate to encourage an appropriate decision (quote 23, table 4). Discussion outcomes variedsome successfully persuaded more appropriate decisions (quote 24, table 4), whereas others acquiesced to 
external pressure because they feared possible consequences or were unable to convince resolute individuals (quotes 22 and 25, table 4).

\section{ICU prescribing norms}

Local norms influenced clinicians' prescribing. These include informal norms referring to what clinicians believed was locally encouraged and prescribed, official institutional guidelines and AMS policies (table 1), and clinicians' attitudes towards policies in terms of adhering to recommendations.

Consultants shaped informal norms and taught or modelled them to trainees. Following these norms and prescribing consistent with colleagues were believed to signal that one's decisions were defensible. Thus, local norms likely affected anticipated interpersonal prescribing consequences and clinicians' necessity perceptions of protecting themselves with prescriptions.

In hospitals 1 and 4, hasty empiric prescribing was discouraged in favour of identifying the source of infection before prescribing (quote 26, table 4). Hospitals 2 and 4 also banned certain broad-spectrum agents, aiming to prevent AMR development (quote 27, table 4).

Other informal norms arguably motivated suboptimal antibiotic practices. Middle-grade trainees in hospital 2 described patients receiving potentially unnecessary antibiotics, patients receiving broaderspectrum antibiotics than required, and an unwillingness to stop antibiotics until after a 5 -day course. These trainees reported reluctantly following these norms; they would prefer to use fewer broad-spectrum antibiotics and to stop antibiotics sooner if patients had clinically improved (quotes 28-29, table 4).

Units also differed in attitudes towards institutional guidelines. Clinicians in hospitals 2, 3 and 4 believed guidelines must be followed, with consultants sometimes reprimanding guideline deviations. Conversely, hospital 1 clinicians believed that guidelines did not have to be strictly followed (quotes 27 and 30-31, table 4). Variation in adherence beliefs may result from whether clinicians saw guidelines as flexible enough to individualise patient care. Clinicians in units with strict adherence beliefs tended to see guidelines as sufficiently tailored for their patient population, whereas doctors in units with less stringent adherence norms tended to see guidelines as less tailored to individual patients.

\section{DISCUSSION}

This is the first study applying NCF to explain ICU antibiotic decision-making. Prescribing decisions were usually made in uncertainty and high stakes due to the significant consequences of antibiotic undertreatment and overtreatment.

Antibiotic decisions were influenced by clinicians' perception of the necessity to prescribe relative to their concerns about the consequences of doing so. Necessity perceptions were strongly influenced by beliefs that antibiotics would protect patients from deterioration and clinicians from ethical, legal and reputational consequences of undertreatment. Similar beliefs were identified by a systematic review of determinants of hospital antibiotic prescribing. ${ }^{10}$

Consistent with previous studies, ${ }^{10}$ our participants commonly cited AMR as a concern. However, AMR was perceived as more distal relative to antibiotic necessity as proximal protection. Similarly, few clinicians identified antibiotic toxicity concerns as key decision-making contributors. Clinicians' strong necessity beliefs and low concerns translated into favouring prescribing or continuing empiric antibiotics, termed 'erring on the side of caution'.

A loss aversion bias may augment this inclination to prescribe. This heuristic is where subjective losses outweigh equivalent potential gains when there are perceived risks and uncertain outcomes, incentivising individuals to behave in a way that minimises their likelihood of experiencing penalties. ${ }^{33} 34$ Clinicians' inclination to prescribe is thus understandable given the immediacy and severity of consequences associated with antibiotic undertreatment compared with those associated with overtreatment. Clinicians are also individually responsible for the consequences associated with undertreatment, whereas the consequences associated with overtreatment are collective. This finding is consistent with previous assertions that the severe consequences of undertreatment for individuals motivate hospital antibiotic overprescription. ${ }^{18}$

Context affected clinicians' inclination to prescribe in uncertainty. Like prior research, prescribing in-hours versus out-of-hours, ${ }^{35}$ input from certain external team members ${ }^{36}$ and prescribing norms ${ }^{37}$ were perceived to influence decision-making. Similarly, prescribers' capabilities, ${ }^{38}$ past experience ${ }^{39}$ and external policy ${ }^{40}$ may affect this behaviour (figure 1). Further research should explore the relationships between these factors.

A repeatedly stated view was that 'complete antibiotic courses' militated against resistance. While the view is valid (eg, in tuberculosis), ${ }^{41}$ it is questionable in the ICU where standard treatment courses (eg, for pneumonias) have been progressively shortened ${ }^{42}$ and early termination or de-escalation minimises selection pressure on gut flora, which (rather than the proximate infection) is the likely source of future resistance. If there is no pathogen, completing the course has no possible merit and may cause collateral harm.

\section{Quality and safety recommendations}

Clinicians' perceptions of the proximal need for antibiotics appear to outweigh their antibiotic-related concerns, leading to favouring overprescription in uncertainty. This behaviour is understandable; however, inappropriate empiric antibiotics may increase the risk of death ${ }^{43}$ and may promote AMR. 


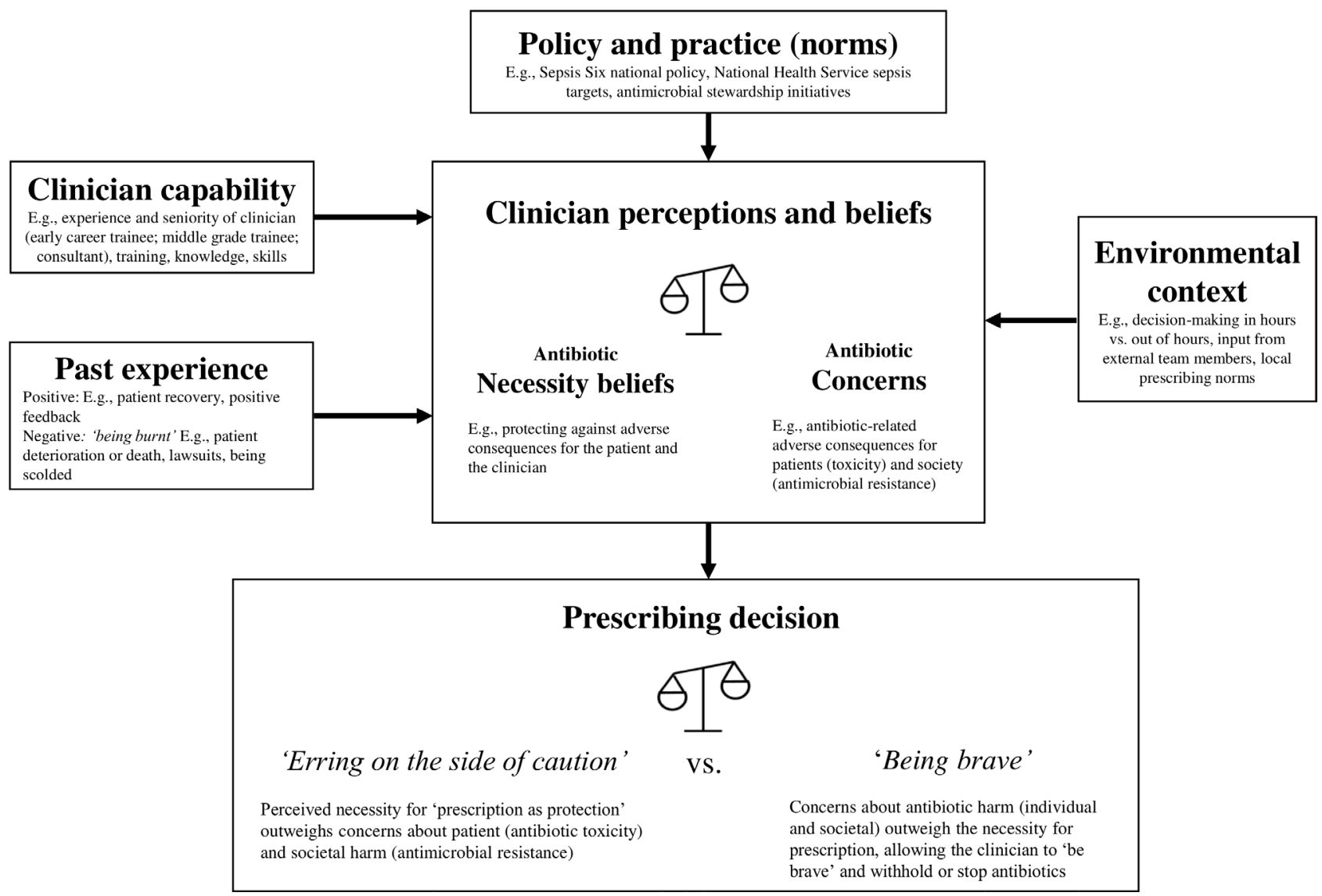

Figure 1 Factors influencing intensive care unit clinicians' antibiotic prescribing in clinical uncertainty.

Our participants recognised AMR's threat; however, they viewed it as distal and did not prioritise it during decision-making.

Our findings have implications for AMS intervention development in ICUs. Interventions designed to increase AMR awareness are less likely to be effective than approaches that address clinicians' necessity concerns evaluation when making prescribing decisions for individual patients. Our participants were concerned about distal AMR, yet prioritised their proximal need to protect against the consequences of not prescribing. Thus, interventions raising clinicians' concerns about potential antibiotic-related harms to the patient are more likely to reduce antibiotic necessity perceptions than general AMR-related messages.

New technology may help reconcile clinicians' beliefs about the necessity to prescribe/not prescribe. Molecular diagnostics can detect bacteria, viruses and antibiotic resistance genes within hours, ${ }^{44}$ rather than the 48-72 hours needed for laboratory culture. Having molecular diagnostic results may encourage clinicians to prescribe narrower-spectrum antibiotics than ordinarily used for empiric therapy, stop antibiotics if a virus and/or no bacterial pathogens are found, and de-escalate to narrow-spectrum antibiotics once a pathogen is identified. Nevertheless, given the potential consequences of undertreatment, clinicians may not trust negative results and may continue empiric antibiotics. In context, clinicians' antibiotic necessity perceptions may explain findings of a lack of difference in intensivist prescribing with and without a highly sensitive rule-out test (ie, one advising discontinuing antibiotics because an infection was unlikely). ${ }^{45}$ Novel information may be insufficient to over-ride established decision-making beliefs; confidence in such systems and interventions increasing the defensibility of non-prescribing should be developed to encourage behaviour change.

Contextual factors can moderate the preference of erring on the side of caution. ICU consultants and microbiologists should continue creating SOS plans to follow out-of-hours and should ensure these accord with AMS principles. Antimicrobial stewards may experience barriers to participation in antibiotic decision-making (eg, limited consultant contact ${ }^{46}$; such obstacles should be assessed and addressed locally. Units should also create norms promoting AMS practices (eg, restricting specific broad-spectrum antibiotics).

\section{Limitations}

This study has limitations. VBIs are self-reports about clinicians' prescribing intentions without real patientrelated or clinician-related consequences. Therefore, participants may answer differently in vignette decisions from how they would have acted with actual patients (eg, in terms of withholding antibiotics). 
While we intentionally designed vignettes with no correct answers to encourage reflection in uncertainty, future research using vignettes with 'correct' responses may better understand factors associated with inappropriate prescribing.

We investigated prescribing in English ICUs. We recognise that Hulscher and colleagues' review $^{12}$ included national culture, and that developed and developing nations have differing drivers to AMR development. ${ }^{47}$ More research should explore antibiotic decision-making in other cultural contexts, including the 'open ICU' model, where patients remain under the care of their primary physician or surgeon rather than intensivists; this model, which is nowhere followed in the UK, has less central control and has been associated with higher infection rates. ${ }^{48}$

We sampled from four hospitals; staff may not fully represent English ICUs. However, these hospitals were selected to ensure diversity and participants would have trained at multiple institutions, so attitudes and behaviours would have evolved from a wider footprint.

Our focus groups included two microbiologists and one infectious disease doctor. Our focus was on ICU bedside clinician decision-making; future studies should explore specialist decision-making.

\section{CONCLUSION}

This is the first study exploring antibiotic decisionmaking in ICU using NCF. When making antibiotic decisions, clinicians must balance important consequences for the individual patient, themselves and the society, under high-stakes and uncertain conditions. Our findings indicate that clinicians favoured erring on the side of caution-prescribing or continuing empiric antibiotics in uncertainty to protect against possible consequences of undertreatment. Clinicians viewed antibiotics' necessity (ie, protection for their patients and themselves) as outweighing concerns about antibiotic toxicity and AMR. Stewardship initiatives are more likely to be effective if they address clinicians' perceptions of antibiotic necessity and increase concerns about antibiotics' potential harmful effects for individual patients.

\footnotetext{
Author affiliations

${ }^{1}$ Centre for Behavioural Medicine, University College London, London, UK ${ }^{2}$ UCLH-UCL Centre for Medicines Optimisation Research and Education, University College London Hospitals NHS Foundation Trust, London, UK ${ }^{3}$ Department of Psychological and Behavioural Science, London School of Economics and Political Science, London, UK

${ }^{4}$ Division of Critical Care, University College London Hospitals NHS Foundation Trust, London, UK

${ }^{5}$ Division of Infection and Immunity, University College London, London, UK ${ }^{6}$ Norwich Medical School, University of East Anglia, Norwich, UK

${ }^{7}$ Department of Medical Microbiology, University College London Hospitals NHS Foundation Trust, London, UK

${ }^{8}$ Department of Surgery and Cancer, Imperial College London, London, UK
}

Acknowledgements We would like to thank all ICU staff who were involved in organising or participating in the research. We also thank Norwich Clinical Trials unit and our Patient and Public Involvement group. This research is supported by researchers and infrastructure at the National Institute for Health Research University College Hospitals and Imperial Biomedical Research Centres. YJ is a Health Foundation Improvement Science Fellow.

Collaborators INHALE WP2 Study Group: authors and their affiliations as above; and Julie Barber and Laura Shallcross, University College London; Jeronimo Cuesta, North Middlesex Hospital; Mark Peters and Nigel Klein, Great Ormond St Hospital and UCL Great Ormond St Institute of Child Health NIHR Biomedical Research Centre; Parvez Moondi, Norfolk and Norwich University Hospitals NHS Foundation Trust; Justin O'Grady, Quadram Institute and University of East Anglia; Juliet High, Charlotte Russell and David Turner, Norwich Clinical Trials Unit, University of East Anglia; and Suveer Singh, Chelsea and Westminster Hospital NHS Foundation Trust.

Contributors This study was conceptualised and designed by RH, SJB, TWR, DB, VIE, DML and VG. Vignettes and interview guides were written by SJB, DB and TWR. Focus groups and interviews were conducted by NB and YJ. Data were analysed by AMP and NB, with input from YJ, SJB, TWR and $\mathrm{RH}$. The manuscript was written by AMP, with input from the remaining authors.

Funding This paper presents independent research funded by the National Institute for Health Research (NIHR) under its Programme Grants for Applied Research Programme (Reference Number: RP-PG-0514-20018). The views expressed are those of the authors and not necessarily those of the National Health Service, the NIHR, or the Department of Health and Social Care.

Competing interests VIE reports personal fees and nonfinancial support from bioMerieux, personal fees from Curetis and non-financial support from Oxford Nanopore Technologies, outside the submitted work. DML reports personal fees from Accelerate, Allecra, Antabio, Astellas, Beckman Coulter, bioMerieux, Cepheid, Centauri, Entasis, Johnson \& Johnson, Meiji, Melinta, Menarini, Mutabilis, Nordic, ParaPharm, QPEX, Roche, Shionogi, Tetraphase, Wockhardt, Zambon, Cardiome and Eumedica. He also reports grants and personal fees from VenatoRx; personal fees and other (shareholder) from GlaxoSmithKline; personal fees and other (stock options) from TAZ; grants, personal fees and other (shareholder) from Merck/MSD and Pfizer; and other (shareholder) from Perkin Elmer and Dechra. All are outside the submitted work.

Patient consent for publication Not required.

Ethics approval This research received ethical approval from the Camden and Kings Cross Research Ethics Committee (16/ LO/1618).

Provenance and peer review Not commissioned; externally peer reviewed.

Data availability statement No data are available.

Supplemental material This content has been supplied by the author(s). It has not been vetted by BMJ Publishing Group Limited (BMJ) and may not have been peer-reviewed. Any opinions or recommendations discussed are solely those of the author(s) and are not endorsed by BMJ. BMJ disclaims all liability and responsibility arising from any reliance placed on the content. Where the content includes any translated material, BMJ does not warrant the accuracy and reliability of the translations (including but not limited to local regulations, clinical guidelines, terminology, drug names and drug dosages), and is not responsible for any error and/or omissions arising from translation and adaptation or otherwise.

Open access This is an open access article distributed in accordance with the Creative Commons Attribution Non Commercial (CC BY-NC 4.0) license, which permits others to distribute, remix, adapt, build upon this work noncommercially, and license their derivative works on different 
terms, provided the original work is properly cited, appropriate credit is given, any changes made indicated, and the use is noncommercial. See: http://creativecommons.org/licenses/by-nc/4. $0 /$.

\section{ORCID iD}

Alyssa M Pandolfo http://orcid.org/0000-0003-0455-496X

\section{REFERENCES}

1 Levin PD, Idrees S, Sprung CL, et al. Antimicrobial use in the ICU: indications and accuracy--an observational trial. J Hosp Med 2012;7:672-8.

2 Kumar A, Ellis P, Arabi Y, et al. Initiation of inappropriate antimicrobial therapy results in a fivefold reduction of survival in human septic shock. Chest 2009;136:1237-48.

3 Mitchell BG, Gardner A. Mortality and Clostridium difficile infection: a review. Antimicrob Resist Infect Control 2012;1:20-6.

4 Moore LSP, Freeman R, Gilchrist MJ, et al. Homogeneity of antimicrobial policy, yet heterogeneity of antimicrobial resistance: antimicrobial non-susceptibility among 108,717 clinical isolates from primary, secondary and tertiary care patients in London. J Antimicrob Chemother 2014;69:3409-22.

5 De Waele JJ, Akova M, Antonelli M, et al. Antimicrobial resistance and antibiotic stewardship programs in the ICU: insistence and persistence in the fight against resistance. A position statement from ESICM/ESCMID/WAAAR round table on multi-drug resistance. Intensive Care Med 2018;44:189-96.

6 Zilahi G, Artigas A, Martin-Loeches I. What's new in multidrug-resistant pathogens in the ICU? Ann Intensive Care 2016;6:96.

7 Fierens J, Depuydt PO, De Waele JJ. A practical approach to clinical antibiotic stewardship in the ICU patient with severe infection. Semin Respir Crit Care Med 2019;40:435-46.

8 Pickens CI, Wunderink RG. Principles and practice of antibiotic stewardship in the ICU. Chest 2019;156:163-71.

9 Versporten A, Zarb P, Caniaux I, et al. Antimicrobial consumption and resistance in adult hospital inpatients in 53 countries: results of an Internet-based global point prevalence survey. Lancet Glob Health 2018;6:e619-29.

10 Warreman EB, Lambregts MMC, Wouters RHP, et al. Determinants of in-hospital antibiotic prescription behaviour: a systematic review and formation of a comprehensive framework. Clin Microbiol Infect 2019;25:538-45.

11 Krockow EM, Colman AM, Chattoe-Brown E, et al. Balancing the risks to individual and society: a systematic review and synthesis of qualitative research on antibiotic prescribing behaviour in hospitals. J Hosp Infect 2019;101:1-12.

12 Hulscher MEJL, Grol RPTM, van der Meer JWM. Antibiotic prescribing in hospitals: a social and behavioural scientific approach. Lancet Infect Dis 2010;10:167-75.

13 Rawson TM, Charani E, Moore LSP, et al. Mapping the decision pathways of acute infection management in secondary care among UK medical physicians: a qualitative study. BMC Med 2016;14:1-10.

14 Broom A, Kirby E, Gibson AF, et al. Myth, manners, and medical ritual: defensive medicine and the fetish of antibiotics. Qual Health Res 2017;27:1994-2005.

15 Livorsi D, Comer A, Matthias MS, et al. Factors influencing antibiotic-prescribing decisions among inpatient physicians: a qualitative investigation. Infect Control Hosp Epidemiol 2015;36:1065-72.
16 Broom A, Broom J, Kirby E, et al. What role do pharmacists play in mediating antibiotic use in hospitals? A qualitative study. BMJ Open 2015;5:e008326.

17 Charani E, Ahmad R, Rawson TM, et al. The differences in antibiotic decision-making between acute surgical and acute medical teams: an ethnographic study of culture and team dynamics. Clin Infect Dis 2019;69:12-20.

18 Tarrant C, Krockow EM, Nakkawita WMID, et al. Moral and contextual dimensions of "inappropriate" antibiotic prescribing in secondary care: a three-country interview study. Front Sociol 2020;5:1-9.

19 Horne R, Chapman SCE, Parham R, et al. Understanding patients' adherence-related Beliefs about Medicines prescribed for long-term conditions: a meta-analytic review of the Necessity-Concerns Framework. PLoS One 2013;8:e80633.

20 National Institute of Health Research Funding and Awards. INHALE: potential of molecular diagnostics for hospitalacquired and ventilator-associated pneumonia in UK critical care, 2016. Available: https://fundingawards.nihr.ac.uk/award/ RP-PG-0514-20018 [Accessed 15 May 2020].

21 O'Brien BC, Harris IB, Beckman TJ, et al. Standards for reporting qualitative research: a synthesis of recommendations. Acad Med 2014;89:1245-51.

22 Schwandt TA. Contextualism. Sage Dict Qual Inq 2011.

23 Morgan DLet al.. Focus groups and social interaction. In: Gubrium JF, Holstein JA, Marvasti AB, eds. The SAGE Handbook of interview research: the complexity of the craft. SAGE Publications, Inc, 2012: 161-76.

24 Evans SC, Roberts MC, Keeley JW, et al. Vignette methodologies for studying clinicians' decision-making: validity, utility, and application in ICD-11 field studies. Int J Clin Heal Psychol 2015;15:160-70.

25 Guest G, Namey E, McKenna K. How many focus groups are enough? building an evidence base for nonprobability sample sizes. Field methods 2017;29:3-22.

26 Saunders B, Sim J, Kingstone T, et al. Saturation in qualitative research: exploring its conceptualization and operationalization. Qual Quant 2018;52:1893-907.

27 Braun V, Clarke V. Thematic Analysis. In: APA Handbook of research methods in psychology. 175, 2018.

28 Glendinning E, Spiers J, Smith JA, et al. A qualitative study to identify perceptual barriers to antiretroviral therapy (ART) uptake and adherence in HIV positive people from UK black African and Caribbean communities. AIDS Behav 2019;23:2514-21.

29 Lambert SD, Loiselle CG. Combining individual interviews and focus groups to enhance data richness. J Adv Nurs 2008;62:228-37.

30 Braun V, Clarke V. Using thematic analysis in psychology. Qual Res Psychol 2006;3:77-101.

31 The UK Sepsis Trust. The sepsis manual: responsible management of sepsis, severe infection, and antimicrobial stewardship, 2017.

32 NICE. Sepsis: quality standard, 2017.

33 Tversky A, Kahneman D. Loss aversion in riskless choice: a reference-dependent model. Q J Econ 1991;106:1039-61.

34 Kahneman D, Tversky A. Prospect theory: an analysis of decision under risk. Econometrica 1979;47:263-91.

35 Kajamaa A, Mattick K, Parker H, et al. Trainee doctors' experiences of common problems in the antibiotic prescribing process: an activity theory analysis of narrative data from UK hospitals. BMJ Open 2019;9:e028733. 
36 Sedrak A, Anpalahan M, Luetsch K. Enablers and barriers to the use of antibiotic guidelines in the assessment and treatment of community-acquired pneumonia-a qualitative study of clinicians' perspectives. Int J Clin Pract 2017;71. doi:10.1111/ ijcp.12959. [Epub ahead of print: 1905 2017].

37 Charani E, Castro-Sanchez E, Sevdalis N, et al. Understanding the determinants of antimicrobial prescribing within hospitals: the role of "prescribing etiquette". Clin Infect Dis 2013;57:188-96.

38 Mattick K, Kelly N, Rees C. A window into the lives of junior doctors: narrative interviews exploring antimicrobial prescribing experiences. J Antimicrob Chemother 2014;69:2274-83.

39 De Souza V, MacFarlane A, Murphy AW, et al. A qualitative study of factors influencing antimicrobial prescribing by non-consultant Hospital doctors. J Antimicrob Chemother 2006;58:840-3.

40 Fitzpatrick F, Tarrant C, Hamilton V, et al. Sepsis and antimicrobial stewardship: two sides of the same coin. BMJ Qual Saf 2019;28:758-61.

41 Vernon A, Fielding K, Savic R, et al. The importance of adherence in tuberculosis treatment clinical trials and its relevance in explanatory and pragmatic trials. PLOS Med 2019;16:1-10.
42 Yahav D, Franceschini E, Koppel F, et al. Seven versus 14 days of antibiotic therapy for uncomplicated gram-negative bacteremia: a noninferiority randomized controlled trial. Clin Infect Dis 2019;69:1091-8.

43 Marquet K, Liesenborgs A, Bergs J, et al. Incidence and outcome of inappropriate in-hospital empiric antibiotics for severe infection: a systematic review and meta-analysis. Crit Care 2015;19:63.

44 Patrinos GP, Danielson PB, Ansorge WJ. Molecular diagnostics: past, present, and future. Molecular Diagnostics 2017:1-11.

45 Hellyer T, McAuley D, Walsh T. Randomised controlled trial and process evaluation of biomarker-guided antibiotic stewardship in suspected ventilator-associated pneumonia. Lancet Respir Med 2019:1-10.

46 Broom J, Broom A, Plage S, et al. Barriers to uptake of antimicrobial advice in a UK Hospital: a qualitative study. $J$ Hosp Infect 2016;93:418-22.

47 Chokshi A, Sifri Z, Cennimo D, et al. Global contributors to antibiotic resistance. J Glob Infect Dis 2019;11:36-42.

48 El-Kersh K, Guardiola J, Cavallazzi R, et al. Open and closed models of intensive care unit have different influences on infectious complications in a tertiary care center: a retrospective data analysis. Am J Infect Control 2016;44:1744-6. 